\title{
Alteration of intercellular adhesion molecule-1 (ICAM-1) expression in the liver and serum level of HBV DNA in chronic hepatitis B patients after interferon treatment
}

\author{
Zheng Rui-dan*, Su Ya-yong, Lu Yan-hui, Meng Jia-rong and Zhang Min-feng \\ Research and Therapy Center for Liver Diseases, Dongnan Hospital affiliated to Xiamen University, \\ Zhang Zhou 363000, Fujian, China. \\ Accepted 19 April, 2011
}

\begin{abstract}
To investigate the intercellular adhesion molecule-1 (ICAM-1) expression in the liver and serum hepatitis $B$ virus (HBV) DNA level in chronic hepatitis $B$ (CHB) patients before and after interferon (IFN) treatment, a total of $51 \mathrm{CHB}$ patients were recruited and treated with IFN- $\alpha 1 \mathrm{~b}$ for 6 months. The expressions of ICAM-1 and serum HBV DNA were determined at baseline and after 6-month treatment by using immunohistochemistry and real time fluorescence polymerase chain reaction (PCR). The expression of ICAM-1 in the patients with moderate to severe CHB was markedly higher that that in mild CHB patients $(P<0.05)$ at baseline and after 6-month treatment. Furthermore, IFN treatment could dramatically decrease the ICAM-1 expression among patients with moderate to severe chronic hepatitis B (CHB) $(P<0.05)$. However, the expression of ICAM-1 was relatively stable in patients with mild CHB even after 6month treatment $(P>0.05)$. In addition, there was a positive correlation between serum level of HBV DNA loads and ICAM-1 expression on hepatocytes in CHB patients, among patients with higher ICAM-1 expression (++, +++, ++++), the serum level of HBV DNA was markedly lowered by IFN- $\alpha 1 b$ treatment $(P<0.05)$, which was not observed in patients only mildly positive for ICAM-1 (+). The results indicate that IFN treatment can down-regulate the expression of ICAM-1 in the liver of CHB patients and promote the clearance of HBV, which was more obvious in patients with higher ICAM-1 expression.
\end{abstract}

Key words: Interferon, hepatitis B, intercellular adhesion molecule-1.

\section{INTRODUCTION}

Hepatitis $B$ is a potentially life-threatening liver infection caused by the hepatitis $B$ virus (HBV). It is a major global health problem and the most serious type of viral hepatitis. It can cause chronic liver disease and puts people at high risk of death from cirrhosis of the liver and liver cancer. Currently, there are no effective antiviral treatments to cure HBV infection in patients with chronic hepatitis B. Seven drugs are licensed in the United States for the treatment of HBV infection: Interferon (IFN) $\alpha$, pegylated IFN $\alpha-2 a$, lamivudine, adefovir, entecavir, telbivudine, and tenofovir (Dienstag, 2008). The

*Corresponding author. E-mail: zhengruidan@tom.com, live.0000@live.cn. effectiveness of IFN for patients with hepatitis $B$ has been widely recognized, and the advantages of IFN include finite duration of treatment, lack of resistant mutants and durable response (Inada and Yokosuka, 2008).

Intercellular adhesion molecule-1 (ICAM-1) is a member of the immunoglobulin superfamily, and an endothelial- and leukocyte-associated transmembrane protein long known for its importance in stabilizing cellcell interactions and facilitating leukocyte endothelial transmigration (Dustin et al., 1986; Wawryk et al., 1989). ICAM-1 acts as the ligand for lymphocyte functionassociated antigen-1 (LFA-1), a receptor found on leukocytes including cytotoxic $T$ cells. Studies have identified ICAM-1 in a varied of inflammation related diseases and researchers consider it a marker of inflammation (Müller et al., 2006; Witkowska, 2005). 
ICAM-1 is critically important to a wide variety of adhesion-dependent leukocyte functions in HBV infection. Whether interferon can directly regulate expression of ICAM-1 and may participate in the immunopathogenesis of HBV infection remain unknown.

Whilst normal human hepatocytes express several cellsurface adhesion molecules, including integrins and cadherins, they express little or no ICAM-1, as determined by immunohistochemistry (Satoh et al., 1994). These cells do, however, often express ICAM-1 during virus infection, autoimmune liver disease and liver allograft rejection. Studies have confirmed HBV can induce the expressions of ICAM-1 in hepatocytes (Hu et al., 1992; Volpes et al., 1992) and ICAM-1 level in the serum correlates with the disease activity of hepatitis $B$ (Knolle et al., 1997). IFN can act as an anti-inflammatory mediator (Maria et al., 2005) and patients treated with IFN have down-regulation of ICAM-1 (García-Monzón et al., 1993). These findings suggested ICAM-1 may be involved in the pathogenesis of HBV induced hepatitis $B$. The present study aimed to investigate the ICAM-1 expressions in the liver and HBV DNA levels before and after treatment with IFN among patients with chronic hepatitis $\mathrm{B}(\mathrm{CHB})$.

\section{PATIENTS AND METHODS}

A total of 51 inpatients (45 males and 6 females) with a mean age of $37.6 \pm 3.2$ years (Range: 18 to 55 years) were recruited from Research and Therapy Center for Liver Diseases, Dongnan Hospital from February 2007 and October 2010. The diagnosis of $\mathrm{CHB}$ was based on the criteria developed by the Chinese Association of Liver Diseases (Chinese Association of Infectious and Parasitic Diseases and Association of Liver Diseases, 2000). These patients weighed $\geq 45 \mathrm{~kg}$, the serum level of alanine aminotransferase (ALT) was 2 - $10 \times$ upper limit of normal (ULN), they were positive for HBsAg for more than 6 months, patients positive for $\mathrm{HBeAg}$ were negative for $\mathrm{HBeAb}$, HBV DNA was $\geq 1 \times$ $10^{5}$ copies $/ \mathrm{ml}$, they had no other infection of hepatitis virus, serum level of total bilirubin $\leq 50 \mu \mathrm{mol} / \mathrm{L}(3 \mathrm{mg} / \mathrm{dl})$, disease condition was stable and drug-induced hepatitis, alcoholic hepatitis and autoimmune hepatitis were excluded. Furthermore, hepatoprotective drugs, enzyme lowing drugs and antiviral drugs were not medicated within 6 months before liver puncture.

\section{Therapeutic regimen}

Patients were intramuscularly treated with IFN- $\alpha 1 \mathrm{~b}\left(5 \times 10^{6} \mathrm{U}\right)$ (Sinogen, Shenzhen Kexing Biotech Co., Ltd) once daily for 2 weeks, and thereafter, once every other day. Treatment was performed for 6 months.

\section{Liver puncture}

Liver puncture was carried out by the same physician with 16guage needle for liver biopsy (Guo et al., 2004). The negative pressure draws a sample of liver tissue which was immediately put into $10 \%$ formaldehyde for fixation. Then, dehydration, embedding and sectioning were performed followed by $\mathrm{H} \& \mathrm{E}$, Masson and reticular fiber staining.

\section{Detection of HBV DNA}

The HBV DNA level was determined by real time fluorescence polymerase chain reaction (PCR) with AG-9600 Thermal station and AG-9600 AMPLISENSOR MINIL YZER (Biotronic, USA). Data were analyzed by the affiliated ASAP software. The reagents and standard HBV DNA were provided by the Biotronic (USA). The asymmetric primers for amplification were as follows: Primer 1: 5'TGTCTCGTGTTACAGGCGGGGT-3' and primer 2: 5'GAGGCATAGCAGCAGGAGA AGAG-3'. The fluorescent primer was 5'-TCGCTGGAAGTGTCTGCGGCGT-3'. One copy was defined as $3.2 \mathrm{~kb}$ HBV DNA in $1 \mathrm{ml}$ of serum, and data were expressed as $\mathrm{N}=10 \times$ copies $/ \mathrm{ml}$.

\section{Detection of ICAM-1 expression in the liver}

The procedures are: (1) The sections were air-dried and treated with 3\% hydrogen peroxide for $10 \mathrm{~min}$; (2) the sections were treated with normal serum for $10 \mathrm{~min}$; (3) sections were incubated with ICAM-1 monoclonal antibody (DAKO, Danmark; $1: 400$ ) at $4^{\circ} \mathrm{C}$ overnight; (4) sections were incubated with secondary antibody at $37^{\circ} \mathrm{C}$ for $1 \mathrm{~h}$; (5) horseradish peroxidase conjugated IgG was added followed by incubation at $37^{\circ} \mathrm{C}$ for $30 \mathrm{~min}$. Before procedures, the sections were washed with phosphate buffered saline (PBS); (6) Visualization was performed with diaminobenzidine (DAB) followed by counterstaining and mounting. Negative controls (ICAM-1 antibody was replaced with PBS) and positive controls were also included. Positive cells had brown granules in the cells and the expression was graded: Negative (-): No positive hepatocytes; slightly positive $(+)$ : Positive hepatocytes <25\%; positive $(++)$ : Positive hepatocytes, 25 to $49 \%$; strong positive (+++): Positive hepatocytes, 50 to $75 \%$; extremely strong positive (++++): Positive hepatocytes $>75 \%$.

\section{Statistical analysis}

Rank sum test, rank correlation analysis and test were carried out for analysis. Statistical analysis was performed with SPSS version 13.0 statistic software package. A value of $\mathrm{P}<0.05$ was considered statistically significant.

\section{RESULTS}

\section{Expression of ICAM-1 before and after IFN treatment in $\mathrm{CHB}$ patients}

The expression of ICAM-1 in the patients with moderate to severe $\mathrm{CHB}$ was markedly higher that that in mild $\mathrm{CHB}$ patients $(\mathrm{P}<0.05)$ at baseline and after 6-month treatment. Furthermore, IFN treatment could dramatically decrease the ICAM-1 expression among patients with moderate to severe CHB $(P<0.05)$. However, the expression of ICAM-1 was relative stable in patients with mild $\mathrm{CHB}$ even after 6 -month treatment with IFN $(P>0.05)$ (Table 1). There is no difference in the age, gender and duration of disease among different groups.

\section{Serum level of HBV DNA before and after IFN treatment}

For 3 patients mildly positive for ICAM-1 (+) before 
Table 1. ICAM-1 expression in the liver before and after IFN treatment.

\begin{tabular}{|c|c|c|c|c|c|c|c|c|c|}
\hline \multirow[b]{3}{*}{ Disease } & \multirow[b]{3}{*}{$\mathbf{N}$} & \multicolumn{8}{|c|}{ ICAM-1 expression } \\
\hline & & \multicolumn{4}{|c|}{ Before treatment } & \multicolumn{4}{|c|}{ After treatment } \\
\hline & & + & ++ & +++ & ++++ & + & ++ & +++ & ++++ \\
\hline Mild CHB & 5 & 2 & 3 & & & 4 & 1 & & \\
\hline Moderate CHB & 19 & & 15 & 4 & & 10 & 6 & 3 & \\
\hline Severe CHB & 21 & 1 & 4 & 5 & 11 & 11 & 6 & 3 & 1 \\
\hline
\end{tabular}

Table 2. Serum HBV DNA level before and after IFN treatment.

\begin{tabular}{lccc}
\hline & & \multicolumn{2}{c}{ Serum HBV DNA level } \\
\hline ICAM-1 expression before treatment & $\mathbf{N}$ & Before & After \\
\hline+ & 3 & $7.3 \pm 1.85$ & $7.1 \pm 1.97$ \\
++ & 22 & $7.6 \pm 1.45$ & $4.8 \pm 1.66$ \\
+++ & 9 & $6.8 \pm 1.35$ & $3.5 \pm 1.03$ \\
++++ & 11 & $6.9 \pm 1.27$ & $2.9 \pm 1.11$ \\
\hline
\end{tabular}

treatment, the serum HBV DNA level was not changed markedly after treatment $(P>0.05)$. For 22 patients positive for ICAM-1 (++), the serum HBV DNA level was significantly decreased after IFN treatment $(P<0.05)$. In addition, in 9 and 11 patients strong positive $(+++)$ and extremely strong positive (++++) for ICAM-1, respectively, the HBV DNA level was also dramatically decreased by IFN treatment $(\mathrm{P}<0.01)$ (Table 2$)$.

\section{DISCUSSION}

ICAM-1 is an important adhesion molecule mediating the interaction between $T$ cells and their target cells. The increase of ICAM-1 expression is beneficial for the adhesion of lymphocytes to the endothelial cells and their migration into the liver, which is a prerequisite of attack of target cells by cytotoxic T lymphocyte (CTL). In addition, the migration of lymphocytes from the blood vessels into the liver plays an important role in the immune response induced liver injury in CHB patients (lannacone et al., 2006). Studies have demonstrated the role of ICAM-1 in the inflammation (Müller et al., 2006; Witkowska, 2005) and ICAM-1 is helpful for the evaluation of hepatic inflammation and the degree of hepatocyte necrosis (Bruno et al., 2005). In healthy HBsAg-positive carriers without inflammatory liver disease, no ICAM-1 expression was found on hepatocytes; in acute hepatitis, ICAM-1 was strongly expressed throughout the liver parenchyma on liver cell membranes and on sinusoidal lining cells. In chronic persistent, chronic active hepatitis and active cirrhosis, ICAM-1 showed membranous positivity on focal clusters of hepatocytes in areas of periportal or intraacinar inflammation (Volpes et al., 1990). Knolle et al. (1997) also found circulating ICAM-1 may be associated with a decrease in liver function that accompanies hepatic disease activity. Our study also showed the presence of significantly increased ICAM-1 expression in $\mathrm{CHB}$ patients and the more severe the $\mathrm{CHB}$, the higher the ICAM-1 expression. In addition, ICAM-1 expression in the liver was decreased after IFN treatment regardless of the disease severity, but the significant decrease was noted in patients with moderate to severe $\mathrm{CHB}$. These findings suggest IFN treatment can down-regulate the hepatic ICAM-1 expression in $\mathrm{CHB}$ patients, which was consistent with the study of García-Monzón et al. (1993).

Volpes et al. (1990) found a lot of HBcAg-positive hepatocytes expressed ICAM-1 on their cell membranes and these cells may represent the "cytotoxic" model. Furthermore, some ICAM-1 positive hepatocytes lacking $\mathrm{HBcAg}$ were found in areas of inflammation, indicating that the virus itself does not directly trigger ICAM-1 expression (Volpes et al., 1990). The HBV infected hepatocytes may secrete a lot of cytokines playing an important role in the expression of ICAM-1 on the surrounding cells. Study also confirmed cytokine can stimulate the expression of ICAM-1 on the hepatocytes (Satoh et al., 1994; Volpes et al., 1992; Schröder et al., 1995). These ICAM-1 positive, HBcAg-negative liver cells might "guide" lymphocytes through the parenchyma toward virally infected target cells.

In addition, after 6-month treatment with IFN, the serum level of HBV DNA was markedly decreased. Moreover, the decrease of serum HBV DNA was related to the hepatic ICAM-1 expression pre-therapy: The higher the ICAM-1 expression, the greater the decrease of HBV DNA following treatment. Serum HBV DNA is an important parameter reflecting the replication of HBV. 
Studies have shown HBV infected patients have higher ICAM-1 expression and favorably respond to IFN treatment. These results indicate increased ICAM-1 expression before treatment can predict good clearance of HBV following treatment, and low or absent expression of ICAM-1 may be a cause of chronicity of hepatitis B (Zheng et al., 2003). In addition, these findings may imply the IFN exert anti-viral effect through regulation of ICAM1 expression (Zheng et al., 2004). Of note, in the present study, there were 6 and 1 patients, strong positive and extremely positive, respectively, for ICAM-1 after 6-month treatment with IFN, and they still had high serum HBV DNA level (mean: $5.4 \pm 1.86$ ). This result may indicate prolongation of course of IFN treatment may be beneficial for HBV clearance when the hepatic ICAM-1 expression stays at a high level following short term IFN treatment. In addition, the ICAM-1 expression in the liver can be used as a predictor of clinical prognosis of CHB (Zhang et al., 2004).

However, the clinical efficacy of anti-viral therapy with IFN is influenced by numerous factors (Janssen et al., 2005), a lot of which are still unclear. The future in depth studies on ICAM-1 may deepen the understanding of the role of IFN in the anti-viral therapy and the role of ICAM-1 in the anti-viral treatment with IFN.

\section{REFERENCES}

Bruno CM, Sciacca C, Cilio D, Bertino G, Marchese AE, Politi G, Chinnici $L$ (2005). Circulating adhesion molecules in patients with virus-related chronic diseases of the liver. World. J. Gastroenterol., 11(29): 4566-4569.

Chinese Association of Infectious and Parasitic Diseases, and Association of Liver Diseases (2000). Guideline for the prevention and treatment of viral hepatitis. Chin. Hepatol., 5(4): 257-263.

Dienstag JL (2008). Hepatitis B virus infection. N. Engl. J. Med., 359(14): 1486-1500

Dustin ML, Rothlein R, Bhan AK, Dinarello CA, Springer TA (1986). Induction by IL 1 and interferon-gamma: tissue distribution, biochemistry, and function of a natural adherence molecule (ICAM-1). J. Immunol., 137(1): 245-254.

García-Monzón C, García-Buey L, García-Sánchez A, Pajares JM, Moreno-Otero R (1993). Down-regulation of intercellular adhesion molecule 1 on hepatocytes in viral chronic hepatitis treated with interferon alfa-2b. Gastroenterology., 105(2): 462-469.

Guo YH, Zhang MF, Meng JR, Lin MZ, Dai TJ (2004). Modification of liver puncture for biopsy. CHIN. J. Clin. Experim. Pathol., 20(6): 747.

$\mathrm{Hu}$ KQ, Yu CH, Vierling JM (1992). Up-regulation of intercellular adhesion molecule 1 transcription by hepatitis $B$ virus $X$ protein. Proc. Natl. Acad. Sci. U S A., 89(23): 11441-11445.

Inada M, Yokosuka O (2008). Current antiviral therapies for chronic hepatitis B. Hepatol. Res., 38(6): 535-542.

lannacone M, Sitia G, Guidotti GL (2006). Pathogenetic and antiviral immune responses against hepatitis B virus. Future. Virol., 1: 189196.

Knolle PA, Eckardt AJ, Protzer-Knolle U, Schirmacher P, Dienes HP, Meyer zum Büschenfelde KH, Gerken G (1997). Circulating ICAM-1 (sCD54) and LFA-3 (sCD58) in chronic hepatitis B--a longitudinal study in patients treated with interferon-alpha. Z. Gastroenterol., 35(6): 459-467.
Janssen $\mathrm{HL}$, van Zonneveld M, Senturk H, Zeuzem S, Akarca US, Cakaloglu Y, Simon C, So TM, Gerken G, de Man RA, Niesters HG, Zondervan P, Hansen B, Schalm SW (2005). HBV 99-01 Study Group; Rotterdam Foundation for Liver Research. Pegylated interferon alfa-2b alone or in combination with lamivudine for $\mathrm{HBeAg}$ positive chronic hepatitis B: a randomised trial. Lancet., 365(9454): 123-129.

Maria Elzbieta SL, Marek LD (2005). Histological outcome of chronic hepatitis B in children treated with interferon alpha. World $\mathrm{J}$. Gastroenterol., 11(45): 7179-7182.

Müller K, Köhn FM, Port M, Abend M, Molls M, Ring J, Meineke V (2006). Intercellular adhesion molecule-1: a consistent inflammatory marker of the cutaneous radiation reaction both in vitro and in vivo. Br. J. Dermatol., 155(4): 670-679.

Satoh S, Nüssler AK, Liu ZZ, Thomson AW (1994). Proinflammatory cytokines and endotoxin stimulate ICAM-1 gene expression and secretion by normal human hepatocytes. Immunol., 82(4): 571-576.

Schröder AJ, Blaheta RA, Scholz M, Kronenberger B, Encke A, Markus $\mathrm{BH}$ (1995). Effects of proinflammatory cytokines on cultivated primary human hepatocytes. Fluorometric measurement of intercellular adhesion molecule-1 and human leukocyte antigen-A, -B, -C, and DR expression. Transplantation, 59(7): 1023-1028.

Volpes R, van den Oord JJ, Desmet VJ (1990). Hepatic expression of intercellular adhesion molecule-1 (ICAM-1) in viral hepatitis $B$. Hepatol., 12(1): 148-154.

Volpes R, van den Oord JJ, Desmet VJ, Yap SH (1992). Induction of intercellular adhesion molecule-I (CD54) on human hepatoma cell line HepG2: influence of cytokines and hepatitis B virus-DNA transfection. Clin. Exp. Immunol., 87(1): 71-75.

Wawryk SO, Novotny JR, Wicks IP, Wilkinson D, Maher D, Salvaris E, Welch K, Fecondo J, Boyd AW (1989). The role of the LFA-1/ICAM-1 interaction in human leukocyte homing and adhesion. Immunol. Rev., 108: 135-161.

Witkowska AM (2005). Soluble ICAM-1: A marker of vascular inflammation and lifestyle. Cytokine., 31(2): 127-34.)

Zhang MF, Meng JR, Zheng RD, Guo YH, Liu HF, Lin MZ (2004). Expression of ICAM-1 and Topo II in liver carcinoma and hepatic cirrhosis. Chin. J. Clin. Experim. Pathol., 20(4): 420-422.

Zheng RD, Xu CR, Zhang XQ, Wang YM (2003). Advance in the relationship between the mutation of intercellular adhesion molecule and the chronicity and severity of hepatitis B. J. Clin. Hepatol., 6(4): 254-255.

Zheng RD, Zhang MF, Rao RC, Yang Z, Huang JD, Xu CR (2004). Serum levels of soluble intercellular adhesion molecule-1 in chronic hepatitis B patients treated with interferon. J. Southeast. China. National. Defence. Med. Sci., 6(6): 417-418, 451. 